$\underline{\text { Artikel Penelitian }}$

\title{
PENGETAHUAN MAHASISWA FAKULTAS KEDOKTERAN UNIVERSITAS PATTIMURA TENTANG GAYA BELAJAR YANG DIMILIKI BERHUBUNGAN DENGAN PRESTASI AKADEMIKNYA DI TAHUN PERTAMA
}

Christiana Rialine Titaley ${ }^{1}$, Yuniasih M. J. Taihuttu ${ }^{1}$, Johan B. Bension ${ }^{1}$, Ressita Fannia Iwan ${ }^{1}$, Inayah Dwi Ruray ${ }^{1}$

${ }^{1}$ Fakultas Kedokteran Universitas Pattimura

Corresponding author e-mail : christiana_rialine@yahoo.com

\begin{abstract}
Abstrak
Pendahuluan. Gaya belajar merupakan cara yang lebih disukai seseorang dalam berpikir, memproses dan memahami suatu informasi. Analisis ini bertujuan untuk melihat hubungan pengetahuan mahasiswa tentang gaya belajarnya dengan prestasi akademik mahasiswa semester pertama Tahun Akademik 2020/2021 di Fakultas Kedokteran Universitas Pattimura (FK UNPATTI). Metode. Analisis ini menggunakan informasi yang berasal dari 169 mahasiswa tahun pertama yang berpartisipasi dalam Survei Gaya Belajar di FK UNPATTI Desember 2020. Variabel terikat adalah prestasi akademik baik yang digambarkan oleh Indeks Prestasi (IP) $\geq 3$. Variabel bebas adalah pengetahuan mahasiswa tentang gaya belajarnya. Variabel perancu yang disertakan adalah jenis kelamin; lokasi asal Sekolah Menengah Atas (SMA); jalur seleksi masuk, dan tempat tinggal responden. Analisis regresi logisitik digunakan untuk mengetahui hubungan variabel bebas dan terikat dengan mempertimbangkan variabel perancu lainnya. Hasil. Sebanyak 57\% mahasiswa tingkat pertama tidak mengetahui jenis gaya belajanya. Odds mendapatkan IP $\geq 3$ lebih tinggi secara signifikan pada mahasiswa yang mengetahui gaya belajarnya dibandingkan yang tidak ( $\mathrm{aOR}=2,49$; 95\%CI: 1,16-5.38) setelah dikontrol dengan faktor perancu. Selain itu, dalam pencapaian IP $\geq 3$ mahasiswa lulusan SMA di wilayah Sulawesi/Kalimantan/Papua memiliki odds yang lebih tinggi (aOR=4.04; 95\%:1,16-14.06), sedangkan mahasiswa dari kabupaten lain di wilayah Maluku di luar Kota Ambon memiliki odds yang lebih rendah $(\mathrm{aOR}=0.36 ; 95 \%: 0,15-0,85)$ dibandingkan mahasiswa lulusan SMA Kota Ambon. Odds mendapatkan IP $\geq 3$ lebih tinggi secara signifikan pada mahasiswa yang berasal dari jalur Seleksi Bersama Masuk Perguruan Tinggi Negeri (aOR=2,56; 95\%:1,12-5,87) dan Seleksi Nasional Masuk Perguruan Tinggi Negeri (aOR=6,37; 95\%:2,06-19,63) dibandingkan jalur Seleksi Mandiri. Kesimpulan. Upaya meningkatkan pemahaman mahasiswa tentang gaya belajar yang dimilikinya penting untuk dilakukan demi meningkatkan prestasi akademik mahasiswa. Penguatan proses seleksi masuk, pendampingan mahasiswa dari jalur Seleksi Mandiri, dan upaya meningkatkan prestasi akademik mahasiswa dari kabupaten lain di Provinsi Maluku perlu mendapatkan perhatian seluruh pemangku kepentingan.
\end{abstract}

Kata Kunci: Gaya belajar, IP, prestasi akademik, mahasiswa.

\section{Abstract}

Introduction. Learning style is a person's preferred way of thinking, processing, and understanding information received. This analysis aims to examine the relationship between students' knowledge about their learning styles and academic achievement of the first semester students in the 2020/2021 Academic Year at the Faculty of Medicine, Pattimura University (FK UNPATTI). Methods. This analysis used information collected from 169 first-year students participating in the Survey of Students' Learning Style at FK UNPATTI, December 2020. The dependent variable is students' academic achievement reflected by the Index Prestasi (IP) or Grade Point Average $(G P A) \geq 3$. The independent variable is students' knowledge about their learning style. The confounding variables included were gender; location of students' high school; selection path of students admission; and type of residence. Logistic regression analyses were performed to determine the relationship between independent and dependent variables by considering confounding variables. Results. We found that $57 \%$ of first-year students did not know their type of learning style. The odds of getting an GPA $\geq 3$ were significantly higher in students knowing their learning style than those who didn't know (aOR=2.49; 95\%CI: 1.16-5.38) after adjusting for confounding variables. Students who graduated from a high school located in Sulawesi/Kalimantan/Papua region had higher odds $(a O R=4.04 ; 95 \%: 1.16-14.06) ;$ while students from high schools located in Maluku Province other than Ambon City had lower odds (aOR=0.36; 95\%: 0.15-0.85) for getting GPA $\geq 3$ than those graduating from a high school located in Ambon City. The odds of getting GPA $\geq 3$ was significantly higher in students admitted in FK UNPATTI from the Seleksi Bersama Masuk Perguruan Tinggi Negeri pathway (aOR=2.56; 95\%:1.12-5.87) and Seleksi Nasional Masuk Perguruan Tinggi Negeri (aOR=6.37; 95\%: 2.06-19.63) compared to the Seleksi 
Mandiri pathway. Conclusions. Efforts to increase students' awareness and understanding of their learning styles are important to improve their academic achievement. Strengthening the admission selection process, mentoring students from the Mandiri Selection pathway, and efforts to improve the academic achievement of high school students from other districts in Maluku Province should be considered by all related stakeholders.

Keywords: Learning styles, IP, academic achievement, student

\section{Pendahuluan}

Konsil Kedokteran Indonesia menetapkan standar bagi seluruh institusi pendidikan kedokteran di Indonesia untuk menggunakan model strategi SPICES, yang merupakan rangkaian strategi pendidikan Student centred, Problem based Integrated/Interprofessional education, Community based, Elective/Early clinical exposure dan Systematic. Student centred berfokus pada kebutuhan, kemampuan, dan gaya belajar mahasiswa, dengan dosen lebih berperan sebagai fasilitator atau dalam proses pembelajaran. ${ }^{1}$

Gaya belajar merupakan cara yang lebih disukai seseorang dalam melakukan kegiatan berpikir, memproses dan memahami suatu informasi. ${ }^{2}$ Gaya belajar merupakan sebuah cara konsisten yang dilakukan peserta didik untuk menangkap stimulus maupun informasi, termasuk mengingat, berpikir dan memecahkan soal. ${ }^{3}$ Gaya belajar juga didefinisikan sebagai kombinasi dari bagaimana seorang peserta didik menyerap informasi dan kemudian mengatur serta mengolah informasi tersebut. ${ }^{4}$ Keefe mendefinisikan gaya belajar sebagai gabungan dari karakteristik kognitif, afektif, dan fisiologis yang berfungsi sebagai indikator tentang bagaimana seseorang mempersepsikan, berinteraksi, dan berespon terhadap lingkungan belajar. $^{5}$
Gaya belajar sangat berpengaruh dalam proses belajar mengajar. Ketika peserta didik memahami gaya belajarnya maka mereka akan lebih cepat dan mudah menerima informasi ataupun pengetahuan baru. ${ }^{6}$ Gaya belajar menurut Fleming dan Mills dalam Othman N, ${ }^{7}$ dibagi menjadi empat jenis, yaitu $\operatorname{visual}(V)$, auditory $(A), \quad$ read/write $(R), \quad$ kinesthetic $(K){ }^{7}$ Setiap gaya belajar memiliki karakteristik yang berbeda. ${ }^{8}$ Gaya belajar visual merupakan gaya belajar yang mengandalakan kemampuan penglihatan, biasanya menggunakan diagram, gambar, dan video. ${ }^{8,9}$ Gaya belajar auditori merupakan gaya belajar yang mengandalkan pendengaran. ${ }^{9}$ Mereka dengan gaya belajar ini senang untuk membicarakan tentang idenya kepada orang lain, begitu pula sebaliknya. ${ }^{8}$ Gaya belajar read/write mampu memproses informasi yang tertulis lalu membacanya secara berulang-ulang, sehingga buku, jurnal, dan sumber bacaan lain menjadi lebih dibutuhkan. ${ }^{8,9}$ Gaya belajar kinestetik biasanya disebut juga gaya belajar gerak. ${ }^{8,9}$ Mereka dengan gaya belajar ini biasanya menyukai belajar dengan memanfaatkan anggota gerak tubuh dalam proses belajar untuk memahami sesuatu.

Penelitian yang dilakukan oleh Pramesti $\mathrm{NMI}^{10} \mathrm{dkk}$, menyatakan bahwa gaya belajar berpengaruh positif terhadap tingkat http://ojs3.unpatti.ac.id/index.php/moluccamed 
pemahaman seorang mahasiswa. ${ }^{10}$ Menurut De

Porter dan Hernacki dalam Ahisya $\mathrm{H} \mathrm{dkk,}{ }^{11}$ gaya belajar seseorang adalah kunci mengembangkan kinerja dalam pekerjaan, di sekolah, dan dalam situasi antar pribadi. Teori Westwood menyebutkan bahwa gaya belajar dapat mempengaruhi prestasi belajar seseorang. ${ }^{11}$ Seseorang yang mengetahui gaya belajar cenderung memiliki prestasi akademik yang baik. ${ }^{12}$ Menurut penelitian Putri WON, dkk, ${ }^{9}$ setelah mengetahui gaya belajarnya, seseorang dapat memaksimalkan cara belajarnya dengan menggunakan cara yang efektif untuk mencapai prestasi yang diharapkan. ${ }^{9}$

Hasil belajar merupakan hasil penilaian proses belajar siswa atas pencapaian suatu tujuan proses belajar. $^{13}$ Hasil capaian pembelajaran seorang mahasiswa juga dinyatakan dengan Indeks Prestasi (IP), yang merupakan hasil penjumlahan dari seluruh hasil perkalian nilai huruf setiap mata kuliah dengan satuan kredit semester (SKS) mata kuliah tersebut dan kemudian dibagi dengan jumlah mata kuliah yang telah ditempuh. ${ }^{4}$ IP maksimum yang dapat dicapai oleh seorang mahasiswa adalah empat.

Bagi mahasiswa Fakultas Kedokteran Universitas Pattimura Ambon (FK UNPATTI), Ambon, tahun pertama merupakan salah satu tahun yang sangat menentukan kelangsung belajar mahasiswa. Dengan adanya perbedaan proses pembelajaran di tingkat perguruan tinggi dibandingkan tingkat Sekolah Menengah Atas (SMA) maka mahasiswa tingkat pertama Fakultas Kedokteran diharapkan dapat dengan cepat beradaptasi, lebih bersifat aktif dan mandiri dalam proses belajar untuk mencapai prestasi akademik yang baik. Selain itu, di tahun 2020 ini, dengan adanya pandemi COVID-19 maka seluruh proses belajar mengajar hanya dilakukan secara daring. Hal ini menjadi tantangan tersendiri bagi mahasiswa baru ketika menghadapi perubahan sistem belajar dari tingkat SMA ke Perguruan Tinggi. Dengan menggunakan data Survei Gaya Belajar pada mahasiswa yang dilakukan oleh FK UNPATTI pada Desember 2020, analisis ini bertujuan untuk melihat hubungan pengetahuan mahasiswa tentang gaya belajarnya dengan prestasi akademik mahasiswa semester pertama Tahun Akademik 2020/2021 di Program Studi Pendidikan Dokter FK UNPATTI. Analisis ini diharapkan dapat memberikan masukan bagi FK UNPATTI untuk meningkatkan prestasi akademik mahasiswa terutama pada semester awal perkuliahan.

\section{Metode}

Sumber Data

Analisis ini menggunakan data sekunder dari Survei Gaya Belajar yang dilakukan FK UNPATTI, ${ }^{14}$ yang dilakukan pada bulan Desember 2020. Pengumpulan data dilakukan secara daring yang melibatkan seluruh mahasiswa FK UNPATTI (total sampling) dari Program Studi Pendidikan Kedokteran FK UNPATTI.

\section{$\underline{\text { Sampel dan kriteria sampel }}$}

Analisis ini hanya menggunakan informasi yang dikumpulkan dari mahasiswa http://ojs3.unpatti.ac.id/index.php/moluccamed 
tingkat pertama FK UNPATTI. Sebanyak 169 dari 183 mahasiswa yang terdaftar di FK UNPATTI yang menjawab pertanyaan survei. Seluruh mahasiswa tingkat pertama yang menjawab pertanyaan survei dilibatkan dalam penelitian ini.

$\underline{\text { Instrumen penelitian }}$

Data yang digunakan dalam analisis ini berasal dari bagian pertanyan sosio-demografi serta gaya belajar mahasiswa. Pertanyaan tentang gaya belajar merupakan terjemahan dari kuesioner VARK (visual (V), auditory $(A)$, read/write $(R)$ dan kinesthetic $(K))$ yang dikembangkan oleh Fleming, ${ }^{7}$ dan sudah tervalidasi. Kuesioner ini kemudian diterjemahkan dari Bahasa Inggris ke Bahasa Indonesia. Kuesioner ini berisi 16 pertanyaan, dengan empat pilihan jawaban untuk setiap pertanyaan. Data prestasi akademik diwakili dengan nilai IP mahasiswa yang diperoleh dari Program Studi Pendidikan Kedokteran FK UNPATTI.

Prosedur Pengumpulan Data

Sebelum pengumpulan data dilakukan, kuesioner ditransfer ke dalam bentuk Google Form. Tautan google form kemudian disebarkan kepada seluruh mahasiswa FK UNPATTI. Seorang data manajer bertugas untuk memastikan kelengkapan data yang masuk ke dalam system dan melaporkannya kepada tim penelitian.

$\underline{\text { Variabel Terikat dan Variabel Prediktor }}$

Variabel terikat dalam penelitian ini adalah IP $\geq 3$ untuk mahasiswa tingkat pertama di FK UNPATTI. Nilai IP mahasiswa dihitung dengan cara menjumlahkan seluruh hasil perkalian nilai huruf setiap mata kuliah yang ditempuh dengan SKS mata kuliah tersebut, dan kemudian dibagi dengan jumlah mata kuliah yang telah ditempuh. Nilai IP untuk semester pertama dihitung oleh Prodi Pendidikan Kedokteran FK UNPATTI.

Variabel prediktor dalam analisis ini adalah pengetahuan mahasiswa tentang gaya belajar yang dimilikinya. Responden dikatakan "mengetahui gaya belajar yang dimilikinya" apabila terdapat kecocokkan antara gaya belajar yang responden sebutkan diawal, dengan kesimpulan gaya belajar berdasarkan kuesioner VARK. Sebaliknya, responden dikatakan "tidak mengetahui gaya belajar yang dimilikinya", apabila gaya belajar yang responden sebutkan diawal tidak cocok atau responden menjawab tidak tahu apa gaya belajar yang dimilikinya. Di bagian awal kuesioner, responden akan ditanyakan "Apakah Anda mengetahui gaya belajar yang Anda miliki?", kemudian responden akan diminta untuk menyebutkan gaya belajarnya selama ini. Jawaban responden untuk pertanyaan ini kemudian dibandingkan dengan kesimpulan gaya belajar responden berdasarkan jawaban responden pada kuesioner VARK yang ditanyakan selanjutnya.

Analisis ini juga menyertakan beberapa faktor yang mungkin menjadi variabel perancu yaitu jenis kelamin (laki-laki/perempuan); lokasi asal SMA (Kota Ambon/kabupaten lain di Provinsi Maluku/Sumatera, Jawa, Bali/Sulawesi, Kalimantan dan Papua); jalur seleksi masuk ke FK UNPATTI (Seleksi Nasional Masuk Perguruan Tinggi Negeri http://ojs3.unpatti.ac.id/index.php/moluccamed 
(SNMPTN); Seleksi Bersama Masuk Perguruan Tinggi Negeri (SBMPTN); dan Seleksi Mandiri), serta jenis tempat tinggal responden (asrama atau kos/tinggal bersama orang tua/tinggal bersama saudara).

$\underline{\text { Analisis Data }}$

Di tahap pertama, frekuensi distribusi setiap variabel disajikan secara deskriptif. Di tahap kedua, analisis regresi logistik (univariat dan multivariat) dilakukan untuk mengetahui hubungan pengetahuan mahasiswa mengenai gaya belajar yang dimiliki dengan IP mahasiswa semester pertama. Analisis regisresi logistik univariat digunakan untuk melihat hubungan setiap variabel yang diteliti dengan IP mahasiswa.

Di tahap awal analisis multivariat, seluruh variabel disertakan untuk melihat hubungan antara pengetahuan mahasiswa tentang gaya belajar yang dimilikinya dan IP, dengan mengontrol semua variabel yang mungkin dapat menjadi perancu. Metode "backward elimintation" kemudian digunakan untuk mengeluarkan variabel non-perancu (batasan nilai signifikasi 0,05). Variabel kontrol yang berhubungan secara signifikan dengan IP $\geq 3$, atau yang dianggap sebagai perancu dipertahankan dalam model akhir. Seluruh variabel sosio-demografi dipertahankan dalam model akhir. Analisis data dilakukan dengan menggunakan software STATA versi 16.

Etika Penelitian

Analisis ini telah disetujui oleh Komisi Etik Penelitian Kedokteran dan Kesehatan FK UNPATTI dengan nomor: 018/FKKOM.ETIK/VIII/2021.

\section{Hasil}

Analisis ini menggunakan informasi yang berasal 169 (92.3\%) mahasiswa tahun pertama Tahun Akademik 2020/2021 di FK UNPATTI yang mengisi kuesioner online. Tabel 1 menunjukkan latar belakang sosiodemografi seluruh responden yang mengisi kuesioner. Lebih dari 76\% mahasiswa adalah perempuan, $38.5 \%$ berasal dari Kota Ambon dan 32\% berasal dari luar Provinsi Maluku. Kurang lebih $48 \%$ mahasiswa berasal dari jalur SBMPN.

Tabel 1. Frekuensi distribusi faktor yang disertakan dalam analisis

\begin{tabular}{|c|c|c|c|c|c|c|}
\hline \multirow{3}{*}{ Variabel } & \multirow{3}{*}{$\mathbf{n}$} & \multirow{3}{*}{$\%$} & \multicolumn{4}{|c|}{ Indeks Prestasi Kumulatif } \\
\hline & & & \multicolumn{2}{|c|}{$<3,00$} & \multicolumn{2}{|c|}{$>=3,00$} \\
\hline & & & $\mathbf{n}$ & $\%$ & $\mathbf{n}$ & $\%$ \\
\hline \multicolumn{7}{|l|}{ Data sosio-demografi } \\
\hline \multicolumn{7}{|l|}{ Jenis Kelamin } \\
\hline Perempuan & 129 & 76.33 & 50 & 38.76 & 79 & 61.24 \\
\hline Laki-laki & 40 & 23.67 & 9 & 22.5 & 31 & 77.5 \\
\hline \multicolumn{7}{|l|}{ Kabupaten Asal SMA } \\
\hline Kota Ambon & 65 & 38.46 & 21 & 32.31 & 44 & 67.69 \\
\hline Kabupaten di Maluku & 49 & 29.00 & 29 & 59.18 & 20 & 40.82 \\
\hline Sumatera/Jawa/Bali & 24 & 14.20 & 5 & 20.83 & 19 & 79.17 \\
\hline Sulawesi/Kalimantan/Papua & 31 & 18.34 & 4 & 12.90 & 27 & 87.10 \\
\hline \multicolumn{7}{|l|}{ Jalur Seleksi masuk FK } \\
\hline Mandiri & 59 & 34.91 & 34 & 57.63 & 25 & 42.37 \\
\hline
\end{tabular}




\begin{tabular}{|c|c|c|c|c|c|c|}
\hline \multirow{3}{*}{ Variabel } & \multirow{3}{*}{$\mathbf{n}$} & \multirow{3}{*}{$\%$} & \multicolumn{4}{|c|}{ Indeks Prestasi Kumulatif } \\
\hline & & & \multicolumn{2}{|c|}{$<3,00$} & \multicolumn{2}{|c|}{$>=3,00$} \\
\hline & & & $\mathbf{n}$ & $\%$ & $\mathbf{n}$ & $\%$ \\
\hline SBMPTN & 82 & 48.52 & 19 & 23.17 & 63 & 76.83 \\
\hline SNMPTN & 28 & 16.57 & 6 & 21.43 & 22 & 78.57 \\
\hline \multicolumn{7}{|l|}{ Tipe tempat tinggal } \\
\hline Kost/asrama & 73 & 43.19 & 30 & 41.10 & 43 & 58.90 \\
\hline Bersama orang tua & 75 & 44.38 & 24 & 32.00 & 51 & 68.00 \\
\hline Bersama saudara & 21 & 12.43 & 5 & 23.81 & 16 & 76.19 \\
\hline \multicolumn{7}{|l|}{ Gaya Belajar } \\
\hline \multicolumn{7}{|c|}{ Apakah Saya Mengenali Gaya Belajar Saya } \\
\hline Tidak & 16 & 9.47 & 7 & 43.75 & 9 & 56.25 \\
\hline Ya & 153 & 90.53 & 52 & 33.99 & 101 & 66.01 \\
\hline \multicolumn{7}{|c|}{ Kecocokan antara pengakuan mahasiswa dengan hasil pengisian kuesioner VARK } \\
\hline Sangat Tidak Cocok & 97 & 57.40 & 40 & 41.24 & 57 & 58.76 \\
\hline Cocok & 72 & 42.60 & 19 & 26.39 & 53 & 73.61 \\
\hline
\end{tabular}

Distribusi gaya belajar mahasiswa berdasarkan penilaian dengan menggunakan kuesioner VARK dapat dilihat pada Gambar 1. Analisis ini menunjukkan bahwa lebih dari separuh mahasiswa tidak mengetahui jenis gaya belajar yang dimilikinya. Hal ini tergambar dari adanya ketidakcocokkan antara pegakuan responden tentang jenis gaya belajar yang dimilikinya dan penilaian gaya belajar menurut kuesioner VARK pada 57\% responden. Gambar 2 menunjukkan distribusi responden pengetahuan mahasiswa tentang gaya belajar yang dimiliki dan kecocokan dengan hasil kuesioner VARK.

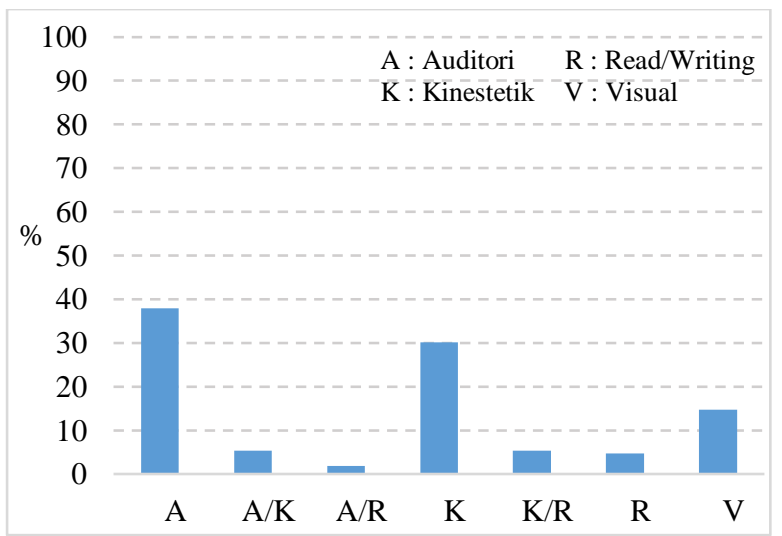

Gambar 1. Distribusi Responden Berdasarkan Gaya Belajar menurut kuesioner VARK

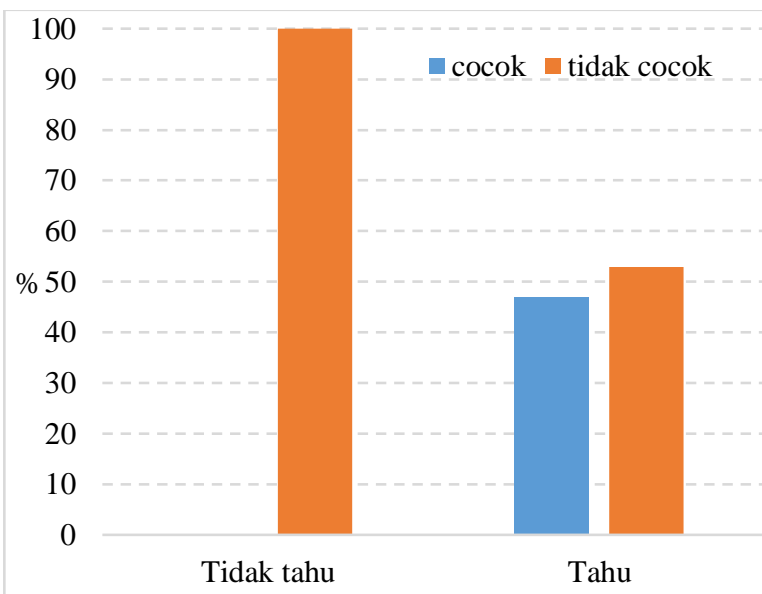

Gambar 2. Distribusi Responden Berdasarkan Pengetahuan Mahasiswa Tentang Gaya Belajar Yang Dimilikinya Dan Kecocokannya Dengan Penilaian Gaya Belajar Mahasiswa Menggunakan Kuesioner VARK

Gambar 3 menunjukkan distribusi responden menurut besaran IP. Untuk persentase setiap variabel yang diteliti menurut IP dapat dilihat pada Tabel 1. Menarik untuk dilihat bahwa persentase IP $\geq 3$ lebih tinggi pada mahasiswa yang masuk dengan menggunakan jalur SNMPTN dibandingkan jalur lainnya. Persentase yang IP $\geq 3$ juga lebih tinggi pada mahasiswa yang mengetahui gaya belajar yang dimiliki, baik berdasarkan 
pengakuan maupun setelah melakukan pengisian VARK (“cocok”).

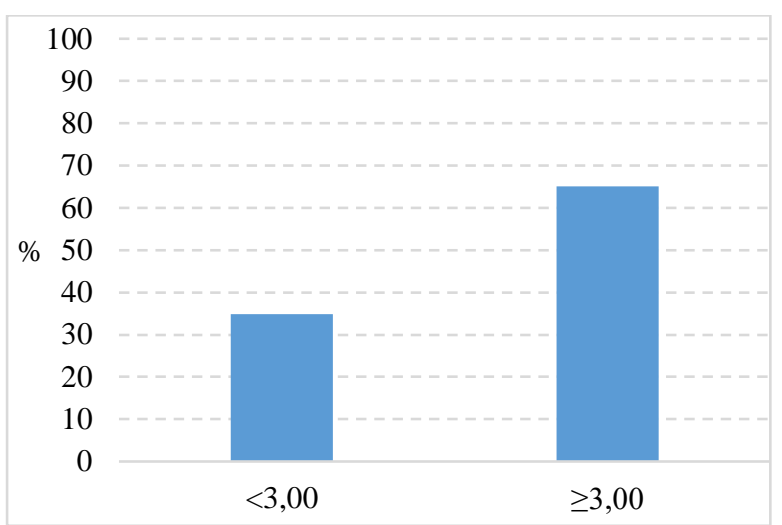

Gambar 3. Distribusi Responden Berdasarkan Indeks Prestasi Semester Pertama
Tabel 2 menunjukkan adanya hubungan yang signifikan antara faktor pengetahuan mahasiswa tentang gaya belajar yang dimiliki dengan pencapaian IP $\geq 3$. Odds pencapaian IP $\geq 3$ pada mahasiswa yang mengetahui gaya belajar yang dimiliki hampir 2,5 kali odds dari mahasiswa yang tidak mengetahui gaya belajar yang dimiliki $(\mathrm{aOR}=2,49$; 95\% CI: 1,16-5.38; $p=0,020)$, setelah dikontrol variabel perancu lokasi asal SMA serta jalur seleksi masuk ke FK UNPATTI.

Tabel 2. Faktor yang berhubungan dengan indeks prestasi kumulatif mahasiswa semester pertama Fakultas Kedokteran Universitas Pattimura, 2020

\begin{tabular}{|c|c|c|c|c|c|c|c|c|}
\hline & \multicolumn{4}{|c|}{ Bivariat } & \multicolumn{4}{|c|}{ Multivariat } \\
\hline & OR & \multicolumn{2}{|c|}{$95 \% \mathrm{CI}$} & $p$ & OR & \multicolumn{2}{|c|}{$95 \% \mathrm{CI}$} & $p$ \\
\hline \multicolumn{9}{|l|}{ Data sosio-demografi } \\
\hline \multicolumn{9}{|l|}{ Jenis Kelamin } \\
\hline Laki-laki & 1.00 & & & & 1.00 & & & \\
\hline Perempuan & 2.18 & 0.96 & 4.96 & 0.063 & 2.28 & 0.90 & 5.79 & 0.083 \\
\hline \multicolumn{9}{|l|}{ Kabupaten Asal SMA } \\
\hline Kota Ambon & 1.00 & & & & 1.00 & & & \\
\hline Kabupaten di Maluku & 0.33 & 0.15 & 0.71 & 0.005 & 0.36 & 0.15 & 0.85 & 0.020 \\
\hline Sumatra/Jawa/Bali & 1.81 & 0.60 & 5.52 & 0.295 & 1.87 & 0.55 & 6.31 & 0.315 \\
\hline Sulawesi/Kalimantan/Papua & 3.22 & 1.00 & 10.40 & 0.050 & 4.04 & 1.16 & 14.06 & 0.028 \\
\hline \multicolumn{9}{|l|}{ Jalur Seleksi masuk FK } \\
\hline Mandiri & 1.00 & & & & 1.00 & & & \\
\hline SBMPTN & 4.51 & 2.18 & 9.34 & $<0.001$ & 2.56 & 1.12 & 5.87 & 0.026 \\
\hline SNMPTN & 4.99 & 1.76 & 14.11 & 0.002 & 6.37 & 2.06 & 19.63 & 0.001 \\
\hline \multicolumn{9}{|l|}{ Tipe tempat tinggal } \\
\hline Kost/asrama & 1.00 & & & & & & & \\
\hline Bersama orang tua & 1.48 & 0.76 & 2.91 & 0.251 & & & & \\
\hline Bersama saudara & 2.23 & 0.74 & 6.76 & 0.155 & & & & \\
\hline \multicolumn{9}{|l|}{ Gaya belajar } \\
\hline \multicolumn{9}{|c|}{ Kecocokan antara pengakuan mahasiswa dengan hasil pengisian keusioner VARK } \\
\hline Tidak cocok & 1.00 & & & & 1.00 & & & \\
\hline Cocok & 1.96 & 1.01 & 3.79 & 0.047 & 2.49 & 1.16 & 5.38 & 0.020 \\
\hline
\end{tabular}

Lokasi asal SMA mahasiswa berhubungan secara signifikan dengan pencapaian IP $\geq 3$. Mahasiswa yang lokasi SMA-nya berada di wilayah
Sulawesi/Kalimantan/Papua memiliki odds yang lebih tinggi untuk memperoleh IP $\geq 3$ dibandingkan mahasiswa dari Kota Ambon $(\mathrm{aOR}=4.04 ; \quad 95 \%: 1,16-14.06 ; \quad p=0,028)$. 
Sebaliknya mahasiswa yang berasal dari kabupaten lain di wilayah Maluku di luar Kota Ambon memiliki odds yang lebih rendah untuk memperoleh IP $\geq 3(\mathrm{aOR}=0.36 ; 95 \%: 0,15-$ $0,85 ; p=0,020)$.

Variabel perancu yang lain dalam analisis ini adalah jalur seleksi mahasiswa ketika diterima di FK UNPATTI. Dibandingkan mahasiswa yang masuk melalui jalur Seleksi Mandiri, mahasiswa yang masuk dengan jalur SBMPTN memiliki odds yang lebih tinggi untuk memperoleh $\mathrm{IP} \geq 3$ (aOR= 2,56; 95\%:1,12-5,87; $p=0,026$ ). Selain itu, mahasiswa yang masuk dengan jalur SNMPTN juga memiliki odds yang lebih tinggi $(\mathrm{aOR}=$ $6,37 ; \quad 95 \%: 2,06-19,63 ; \quad p=0,001) \quad$ untuk mencapai IP $\geq 3$.

\section{Pembahasan}

Temuan utama

Studi ini menunjukkan adanya hubungan yang signifikan antara pengetahuan mahasiswa tentang gaya belajar yang dimilikinya dengan prestasi akademik mahasiswa tahun pertama di FK UNPATTI. Prestasi akademik mahasiswa cenderung menjadi lebih baik ketika mahasiswa mengetahui gaya belajar yang dimiliknya. Selain gaya belajar, faktor yang berhubungan dengan prestasi akademik adalah kabupaten yang menjadi lokasi SMA serta jalur seleksi masuk mahasiswa ke FK UNPATTI. Hasil studi ini diharapkan dapat menjadi masukan bagi institusi tentang pentingnya meningkatkan pemahaman mahasiswa tentang gaya belajar yang dimilikinya sebagai bagian dari upaya meningkatkan prestasi akademik mahasiswa, terutama di tahun pertama.

Hubungan gaya belajar dengan presetasi akademik

Penelitian ini menunjukkan adanya hubungan yang signifikan antara pengetahuan mahasiswa tentang gaya belajar yang dimiliki dengan prestasi akademiknya. Mahasiswa yang mengetahui gaya belajarnya akan cenderung menunjukkan prestasi akademik yang lebih baik, dibandingkan mahasiswa yang tidak mengetahui gaya belajar yang dimilikinya. Hasil ini sesuai dengan penelitian Pramesti $\mathrm{dkk},{ }^{10}$ bahwa gaya belajar berpengaruh positif terhadap tingkat pemahaman mahasiswa. ${ }^{10}$ Hasil ini juga didukung oleh berbagai studi lainnya yang menyebutkan bahwa bila seseorang mengetahui gaya belajarnya maka akan meningkatkan kemampuan untuk belajar secara lebih efektif, lebih dapat memanfaatkan kemampuan belajarnya secara lebih optimal, dan akhirnya akan meningkatkan prestasi akademiknya. ${ }^{15-17}$ Ketika mahasiswa belajar dengan metode yang sesuai dengan gaya belajar yang dimilikinya, proses belajar akan lebih mudah, cepat dan dengan hasil yang baik. ${ }^{18}$ Mahasiswa dapat memaksimalkan hasil belajar dengan menetapkan cara belajar yang efektif sesuai dengan gaya belajarnya. ${ }^{9}$ Selain itu, disebutkan juga bahwa mahasiswa yang mengetahui gaya belajarnya akan lebih percaya diri, mengetahui kelebihan dan kekurangan diri sendiri dan membuat proses belajar lebih menyenangkan. ${ }^{18}$ Penelitian yang lain juga menyatakan bahwa, mahasiswa yang belajar 
sesuai dengan prefensi sensorinya memiliki hasil yang lebih baik. ${ }^{12}$

Hasil penelitian ini menunjukkan masih ada mahasiswa tahun pertama FK UNPATTI yang belum mengetahui cara belajar yang dimiliki. Identifikasi ini penting dilakukan sedini mungkin sehingga agar dapat membantu mahasiswa melakukan pembelajaran di perguruan tinggi pada tahun pertama yang merupakan transisi sistem akademik dari tingkat SMA ke Perguruan Tinggi. Peran insitusi menjadi sangat penting untuk membantu membantu mahasiswa mengenali gaya belajarnya. Berbagai instrumen dapat digunakan agar mahasiswa mampu mengidentifikasi gaya belajarnya sendiri. Kuesioner $\operatorname{VARK}^{7}$ yang digunakan dalam penelitian ini menjadi salah satu alternatif instrumen yang digunakan. Pengenalan gaya belajar sebaiknya diintegrasikan di fase awal perkuliahan, misalnya saat orientasi pengenalan kehidupan kampus maupun ketika kegiatan matrikulasi (pembekalan) dilakukan sebelum perkuliahan dimulai. Di samping itu, dengan kondisi pandemi COVID-19 yang mengharuskan seluruh kegiatan belajar mengajar dilakukan secara daring maka hal ini menjadi tantangan tersendiri bagi institusi. Tanpa adanya interaksi antar mahasiswa seperti ketika seluruh aktifitas akademik dilakukan secara luring, mahasiswa dituntut untuk tetap mampu beradaptasi secara lebih mandiri dengan sistem pembelajaran perguruan tinggi. Kondisi ini diharapkan juga memacu institusi agar lebih inovatif dan cermat melakukan intervensi efektif agar mahasiswa memperoleh hasil belajar yang baik, termasuk upaya mendorong mahasiswa mengenali dan memanfaatkan gaya belajar yang dimilikinya secara optimal.

Pemahaman gaya belajar bukan hanya penting bagi peserta didik, namun juga bagi tenaga pendidik. Kurang pahamnya tenaga pendidik dengan gaya belajar peserta didik dapat merugikan selama proses pembelajaran. Ketika seorang pendidik mengetahui gaya belajar yang dimiliki peserta didiknya, maka pendidik melakukan kegiatan pengajaran lebih efisien dan memfasilitasi proses belajar mengajar secara lebih baik. ${ }^{19}$ Pendidik dapat mempersiapkan metode pembelajaran yang bervariasi sesuai dengan gaya belajar peserta didik agar materi yang diberikan dapat dengan lebih mudah dipahami. Penelitian menunjukkan ketika para pendidik menyesuaikan metode pembelajaran dengan gaya belajar peserta didiknya, maka prestasi akademik peserta didik akan lebih baik. ${ }^{18,20-22}$ Faktor lain yang berhubungan dengan prestasi akademik mahasiswa

Dalam penelitian ini, selain pengetahuan tentang gaya belajar seseorang, asal kabupaten tempat SMA berasal juga berhubungan dengan prestasi akademik mahasiswa. Mahasiswa FK UNPATTI yang berasal dari kabupaten lain di Provinsi Maluku selain Kota Ambon memiliki kecenderungan memiliki IP yang rendah. Lokasi SMA dapat merefleksikan sistem pendidikan saat bersekolah di tingkat SMA. Hal ini menjadi masukan yang penting baik bagi FK UNPATTI maupun Dinas Pendidikan dan Kebudayaan terkait kualitas lulusan SMA di http://ojs3.unpatti.ac.id/index.php/moluccamed 
berbagai wilayah Provinsi Maluku. Upaya meningkatkan kualitas lulusan di kabupaten lain di luar Kota Ambon perlu menjadi perhatian bersama.

Bagi FK UNPATTI sendiri, kegiatan matrikulasi sebelum perkuliahan dimulai menjadi salah satu kegiatan yang sangat penting untuk terus dilakukan guna menyetarakan kompetensi mahasiswa, ${ }^{23}$ terutama bagi mereka yang berasal dari kabupaten di luar Kota Ambon. Melalui kegiatan matrikuasi, mahasiswa diharapkan memiliki bekal pengetahuan yang lebih baik untuk merencanakan dan melaksanakan pembelajaran di tingkat perguruan tinggi. ${ }^{24}$ Sebuah studi yang dilakukan di Fakultas Bahasa dan Seni Universitas Negeri Yogyakarta menunjukkan bahwa nilai rerata salah satu mata kuliah dasar lebih tinggi pada mahasiswa yang mengikuti program matrikulasi dibandingkan mereka yang tidak mengikuti program matrikulasi. ${ }^{25}$ Kegiatan matrikulasi di FK UNPATTI hendaknya dapat terus dilaksanakan dan dimanfaatkan secara optimal. Evaluasi kegiatan matrikulasi hendaknya dapat terus dilaksanakan untuk memperoleh hasil belajar yang lebih maksimal bagi seluruh mahasiwa.

Hasil penelitian ini juga menunjukkan adanya perbedaan prestasi akademik mahasiswa berdasarkan jalur masuk ke FK UNPATTI. Mahasiswa Tahun Akademik 2020/2021 yang masuk melalui jalur SNMPTN cenderung memiliki IP yang lebih tinggi, diikuti mahasiswa dengan jalur masuk SBMPTN. Mahasiswa dengan jalur masuk
Seleksi Mandiri cenderung memiliki IP yang rendah. Walaupun ada penelitian tidak menunjukkan adanya perbedaan prestasi akademik berdasarkan jalur masuk, ${ }^{26}$ beberapa penelitian juga menunjukkan hasil yang sama dengan penelitian ini. ${ }^{27-29}$ Dalam penelitian yang dilakukan oleh Kadek dkk, ${ }^{27}$ Annizar $\mathrm{dkk},{ }^{28}$ serta Munawaroh $\mathrm{dkk},{ }^{29}$ mahasiswa yang masuk melalui jalur Seleksi Mandiri cenderung menunjukkan prestasi akademik yang lebih rendah dibandingkan jalur masuk lainnya. Hal ini menjadi catatan yang penting bagi insititusi dalam proses penerimaan mahasiswa baru. Selain proses seleksi yang perlu mendapatkan perhatian, pantauan yang lebih ketat dan dukungan yang lebih baik perlu diberikan kepada mahasiswa jalur Seleksi Mandiri. Dukungan akademik misalnya dengan program mentoring khusus dapat dikembangkan untuk membantu mahasiswa yang bermasalah dengan kegiatan belajar di lingkungan kampus untuk mencapai prestasi akademik yang baik.

\section{Kesimpulan}

Pengetahuan mahasiswa tentang gaya belajar yang dimiliki berhubungan dengan prestasi akademik mahasiswa tahun pertama di FK UNPATTI. Selain itu, kabupaten yang menjadi lokasi SMA serta jalur seleksi masuk juga berhubungan dengan prestasi akademik mahasiswa di tahun pertama. Penelitian ini menunjukkan pentingnya upaya identifikasi gaya belajar mahasiswa sebelum perkuliahan dimulai, misalnya dalam kegiatan orientasi mahasiswa baru maupun matrikulasi. Hal ini akan membantu mahasiswa untuk belajar http://ojs3.unpatti.ac.id/index.php/moluccamed 
secara lebih efektif dan staf pengajar untuk melakukan pengajaran secara lebih efisien sehingga prestasi akademik mahasiswa juga menjadi semakin baik. Penguatan proses seleksi masuk jalur Seleksi Mandiri dan pendampingan mahasiswa yang diterima melalui jalur Seleksi Mandiri yang membutuhkan dukungan akademik juga penting untuk menjadi perhatian di tingkat universitas dan fakultas. Prestasi akademik

\section{Referensi}

1. Muhammad SA. Ilmu Kedokteran Dasar. Vol. XII, Jurnal Berkala iImu Kedokteran. 1980.

2. Suhoyo Y. Konsep Inovasi Strategi Pendidikan di Institusi Pendidikan Kedokteran. J Pendidik Kedokt Indones. 2012;1(2):1-10.

3. Adi W, Gunawan G. Genius Learning Strategy: Petunjuk Praktis untuk Menerapkan Accelerated Learning. Jakarta: PT. Gramedia Pustaka Utama; 2003.

4. Nasution S. Berbagai pendekatan dalam proses belajar \& mengajar. Jakarta: PT. Bumi Aksara; 2003.

5. Keefe JW. Learning style: theory and practice. Reston (USA): National Association of Secondary School Principals. 1987.

6. Putri ACS, Malik R. Pengaruh gaya belajar auditori dan visual terhadap kelulusan ujian teori blok Biomedik 2 mahasiswa Fakultas Kedokteran Universitas Tarumanagara semester ganjil 2018. Tarumanagara Med J [Internet]. 2020;2(2):213-7. Available from: https://journal.untar.ac.id/index.php/tmj/a rticle/viewFile/7830/5233

7. Othman N, Amiruddin MH. Different perspectives of learning styles from VARK model. Procedia - Soc Behav Sci. 2010;7(C):652-60.

8. Robertson L, Smellie T, Wilson P, Cox L. Learning Style and Fieldwork Education: Students Perspectives. New Zeal J Occup

mahasiswa asal SMA dari kabupaten lain $\mathrm{d}$ Maluku di luar Kota Ambon yang perlu ditingkatkan juga menjadi masukan penting bagi para pemegang program dan pemangkupentingan terkait dalam meningkatkan kualitas pendidikan praperguruan tinggi dalam upaya menghasilkan lulusan yang lebih berkualitas di wilayah Maluku.

Ther. 2011;58(1):36-40.

9. Putri WON, Rusnayati H, Purwana U. Hubungan Gaya Belajar dengan Hasil Belajar Siswa pada Materi Usaha dan Energi. Pros Semin Nas Fis 60 [Internet]. 2020;108-14. Available from: http://proceedings2.upi.edu/index.php/sin afi/article/view/1254

10. Pramesti NMI, Ratnadi NMD. Pengaruh Kecerdasar Emosional, Gaya Belajar Visual, Gaya Belajar Auditorial dan Kinestetik Pada Tingkat Pemahaman Akuntansi. e-Jurnal Akunt. 2020;30(1):130-46.

11. Ahisya H, Utami D, Supriyati S, Farich A. Gaya Belajar dengan Prestasi Belajar Mahasiswa Fakultas Kedokteran Umum Universitas Malahayat. J Ilm Kesehat Sandi Husada [Internet]. 2020;11(1):1038. Available from: https://akpersandikarsa.e-journal.id/JIKSH

12. Farhan FS, Risdianti E. Pengaruh pemberian metode pembelajaran secara konvensional dan secara preferensi sensori kinestetik terhadap prestasi belajar pada mahasiswa kedokteran universitas Muhammadiyah Jakarta. J Edunmaspul. 2021:5(1):89-95.

13. Aydin L, Ilhan S, Kiziltan E, Yazihan N, Yazici C, Gundogan N. The Influence of Six-Year Medical Education on Learning Styles in Medical Students at Baskeent University. Open Access Libr J. 2015;2(8).

14. Titaley CR, Silalahi PY, Bension JB, 
Huwae LBS. Laporan Akhir: Evaluasi Proses Pembelajaran Online Mahasiswa Selama Masa Pandemi Covid-19: Aspek Sistem Pembelajaran Dan Psikologis Mahasiswa Fakultas Kedokteran Universitas Pattimura. Ambon; 2020.

15. Kumar LR, Chacko TV. Using Appreciative Inquiry to Help Students Identify Strategies to Overcome Handicaps of their Learning Styles. Educ Heal. 2012;25(3):160-4.

16. Lujan HL, DiCarlo SE. First-year medical students prefer multiple learning styles. Adv Physiol Educ. 2006;30(1):13-6.

17. Wulandari R. Hubungan gaya belajar dengan prestasi belajar mahasiswa semester IV program study D IV kebidanan Universitas Sebelas Maret. KesMaDasKa [Internet]. 2011;2(1):4552. Available from: https://www.jurnal.stikeskusumahusada.a c.id/index.php/JK/article/view/14

18. Awla HA. Learning Styles and Their Relation to Teaching Styles. Int J Lang Linguist. 2014;2(3):241-5.

19. Wiedarti P. Seri Manual GLS: Pentingnya Memahami Gaya Belajar. Direktorat Jenderal Pendidikan Dasar dan Menengah Kementerian Pendidikan dan Kebudayaan. Jakarta: Kementerian Pendidikan dan Kebudayaan Republik Indonesia; 2018.

20. Kurniawan MR. Kesesuaian Proses Perkuliahan Dengan Gaya Belajar Mahasiswa Terhadap Prestasi Belajar. TEKNOMEDIKA. 2015;13(2):66-80.

21. Halim A. Pengaruh Stragegi Pembelajaran Dan Gaya Belajar Terhadap Hasil Belajar Fisika Siswa SMP Negeri 2 Secanggang Kabupaten Langkat. J TABULARASA PPS UNIMED. 2012;9(2):141-58.

22. Sulistyanto H, Sujalwo S. Pengembangan Media Pembelajaran Berbasis Teknologi Sesuai Dengan Gaya Belajar Peserta
Didik. Simp Nas RAPI XV. 2016;429-35.

23. Kamus Besar Bahasa Indonesia (KBBI) [Internet]. 2021 [cited 2021 May 24]. Available from: https://kbbi.web.id/matrikulasi

24. Anwar Y, Rustaman NY, Widodo A. Kemampuan Subject Specific Pedagogy Calon Guru Biologi Peserta Program Pendidikan Profesional Guru (PPG) Yang Berlatar Belakang Basic Sains Pra dan Post Workshop. J Pendidik IPA Indones. 2012;1(2):157-62.

25. Pusparani M. Perbandingan Prestasi Belajar Vokal 1 Pada Mahasiswa Yang Mengikuti Dan Yang Tidak Mengikuti Program Matrikulasi Di Jurusan Pendidikan Seni Musik Fakultas Bahasa Dan Seni Universitas Negeri Yogyakarta [Internet]. Univeristas Negeri Yogyakarta; 2012. Available from: http://eprints.uny.ac.id/id/eprint/9349

26. Claudya $\mathrm{Y}$, Ngadimin N, Melvina $\mathrm{M}$. Perbedaan Prestasi Belajar Mahasiswa Berdasarkan Jalur Seleksi Masuk Jurusan Pendidikan Fisika Universitas Syiah Kuala. J Ilm Mhs Pendidik Fis [Internet]. 2017;2(3):321-5. Available from: http://www.jim.unsyiah.ac.id/pendidikanfisika/article/viewFile/5670/2335

27. Suwena KR. Jalur Penerimaan Mahasiswa Baru Bukan Penentu Prestasi Belajar Mahasiswa. Ekuitas J Pendidik Ekon. 2017;5(2):1-10.

28. Annizr AM, Arifin M. Perbedaan Prestasi Belajar Mahasiswa Ditinjau dari Jalur Seleksi Masuk Perguruan Tinggi. SAP (Susunan Artik Pendidikan). 2021;5(3).

29. Munawaroh F. Pengaruh Jalur Masuk Terhadap Prestasi Mahasiswa Program Studi Pendidikan IPA Pada Mata Kuliah Dasar Listrik Magnet. J Pena Sains. 2015;2(2):72-8. 